interactions as being truly sex. It seems that even when the brief interaction only includes sexual fondling or kissing, the interaction is felt to be classified as a hookup. Disconcerting for those hopelessly in love with one special person is that friends and acquaintances compromise $70 \%$ of the hookups and even strangers (14\%) had a higher degree of hooking up than did ex-boyfriends (12\%). Of specific interest to the urologist is the notation that condom use was never used for oral sex during these hookups and surprisingly in only $69 \%$ of those interactions involving vaginal sex. This statistic is of particular value to remember when examining a young female patient with the potential presentation of the first occurrence of genital herpes or paroxysmal voiding symptoms. The article is well worth the read especially with regards to the discussion and comparison of the characteristics of the casual affair versus the romantic relationship.

\author{
Dr. Steven P. Petrou \\ Professor of Urology, Associate Dean \\ Mayo School of Graduate Medical Education \\ Jacksonville, Florida, USA \\ E-mail: petrou.steven@mayo.edu
}

doi: 10.1590/S1677-55382010000500027

\title{
Adjustable continence therapy for severe intrinsic sphincter deficiency and recurrent female stress urinary incontinence: long-term experience
}

Kocjancic E, Crivellaro S, Ranzoni S, Bonvini D, Grosseti B, Frea B

Department of Urology, College of Medicine, University of Illinois, Chicago, Illinois 60612, USA

J Urol. 2010; 184: 1017-21

Purpose: Adjustable continence therapy (ACT) was developed to treat female stress urinary incontinence resulting from intrinsic sphincter deficiency by increasing urethral resistance. We evaluated the implantation procedure and assessed patient outcomes at our center.

Materials and Methods: The adjustable continence device consists of 2 silicone balloons on either side of the proximal urethra under the bladder neck, each attached to a titanium port buried in the labia to allow postoperative titration. Urodynamic assessment was done in 57 female patients in whom previous pelvic surgery had failed. Pad use and an incontinence quality of life questionnaire were evaluated before ACT implantation, postoperatively at 1,3,6 and 12 months, and annually thereafter. Patients recorded the overall impression and percent of improvement postoperatively based on the Patient Global Impression Index and a visual analog scale.

Results: Mean follow-up was 72 months (range 12 to 84). At 6-year follow-up in 29 patients mean pad use improved from 5.6 daily at baseline to 0.41 and intrinsic sphincter deficiency improved from 27.2 to 78.6 (p $<0.001$ ). As measured on the visual analog scale, $68 \%$ of patients considered themselves dry. On the Patient Global Impression Index questionnaire 64\% were very much improved, 23\% were much improved and 13\% were only minimally improved or unchanged. No patients considered themselves worse after the procedure. Complications necessitating device removal developed in $21.1 \%$ of patients.

Conclusions: Relative ease of insertion and the ability to tailor this therapy to individual needs makes this an attractive option for the challenging treatment for recurrent stress urinary incontinence due to intrinsic sphincter deficiency.

\section{Editorial Comment}

The authors review their experience with an anti-incontinence device comprised of two silicone balloons which is placed transvaginally and allows for postoperative titration to optimize long-term results. The authors 
were able to achieve a self reported dry rate in $68 \%$ of their patients with a mean follow-up of 72 months. No patient felt that the procedure made them worse.

When reading this article, many will remember the previous anti-incontinence device termed genitourinary spheroidal membranes which were placed approximately 20 years ago (1). The advantage of this contemporary device is the potential for less migration and the ability to postoperatively titrate. In the past, the genitourinary spheroidal membrane effect could be enhanced by placing more membranes spheres paraurethrally; consequently, on occasion there was some dislodgement with proximal migration of the device(s) into the retropubic space. This adjustable continence device is placed and first allowed to form a pseudo capsule prior to beginning the process of balloon adjustment to address the incontinence. This method seems to have limited the complication of dislodgement and optimized the results in this challenging population of patients with very low Valsalva leak point pressures $(<60 \mathrm{~cm}$ water). The device certainly looks appealing and very competitive with injectable therapy but only time will provide the answer whether it will achieve a high level of popularity.

\section{Reference}

1. Darson MF, Malizia AA, Barrett DM: Periurethral injection of the genitourinary spheroidal membrane. J Endourol. 1996; 10: 283-6.

Dr. Steven P. Petrou

Professor of Urology, Associate Dean Mayo School of Graduate Medical Education

Jacksonville, Florida, USA

E-mail:petrou.steven@mayo.edu

\section{PEDIATRIC UROLOGY}

doi: $10.1590 / \mathrm{S} 1677-55382010000500028$

\section{Value of ultrasound in evaluation of infants with first urinary tract infection}

Preda I, Jodal U, Sixt R, Stokland E, Hansson S

Department of Pediatrics, Queen Silvia Children's Hospital, Sahlgrenska Academy, University of Gothenburg, Gothenburg, Sweden

J Urol. 2010; 183: 1984-8

Purpose: We evaluated the role of ultrasound in diagnosing and treating infants with a first urinary tract infection with a focus on important structural abnormalities.

Materials and Methods: In a setting of limited prenatal ultrasound screening this population based, prospective, 3-year study included 161 male and 129 female infants. Ultrasound and dimercapto-succinic acid scintigraphy were performed as initial investigations and voiding cystourethrography was conducted within 2 months.

Results: Ultrasound revealed dilatation in $15 \%$ of patients and increased kidney length in $28 \%$. Sensitivity for detecting scintigraphic abnormality was $48 \%$. Renal length was significantly correlated to inflammatory parameters, including scintigraphic abnormalities. Important structural abnormalities were detected in 40 cases, with 30 on ultrasound, while 10 of 27 cases of dilating reflux (mostly grade III) were missed. Outside the study there were 28 additional cases of structural abnormality, of which 15 were detected prenatally.

Conclusions: Ultrasound detected most structural abnormalities except grade III reflux. Since it is noninvasive, ultrasound has a place in the evaluation of infants with urinary tract infection, especially in the absence of prenatal 